\title{
ВОПРОСЫ БИЗНЕС-ОБРАЗОВАНИЯ
}

УДК: 378

JEL: A2

Ю. Н. Арай, О. Р. Верховская, Т. Н. Клёмина

ОБУЧЕНИЕ СТРАТЕГИИ В БИЗНЕС-ШКОЛАХ: СОВРЕМЕННЫЕ ВЫЗОВЫ

Санкт-Петербургский государственный университет, Российская Федерация, 199034,

Санкт-Петербург, Университетская наб., 7/9

В статье затронута актуальная проблема, с которой сталкиваются бизнес-школы во всем мире: необходимость включения в содержание программы учебной дисциплины, посвященной стратегии, концепций и инструментов стратегического менеджмента, обладающих реальной полезностью для управленческой практики. Ее решение предполагает выявление потребностей тех, кто обучается в бизнес-школах, в получении знаний и навыков в области стратегического управления. В статье представлены результаты пилотного эмпирического исследования, нацеленного на выявление ожиданий слушателей программы «Мастер делового администрирования для руководителей» одной из ведущих российских бизнес-школ в отношении содержания дисциплины «Стратегический менеджмент». Исследование показало, что слушатели связывают источники конкурентного преимущества в основном с лучшей позицией компании во внешней среде и поэтому в большей степени заинтересованы в изучении стратегических инструментов, позволяющих ее диагностировать. Это порождает ряд серьезных вызовов для преподавания дисциплины и ставит вопрос о целесообразности проактивного формирования профессиональных компетенций в области стратегического управления.

Ключевые слова: дисциплина «Стратегический менеджмент», бизнес-школа, обучение менеджеров, методы обучения.

\section{STRATEGY TEACHING AT BUSINESS SCHOOL: CONTEMPORARY CHALLENGES}

\section{Y. N. Aray, O. R. Verkhovskaya, T. N. Klemina}

St. Petersburg State University, 7/9, Universitetskaya nab., St. Petersburg, 199034, Russian Federation

The paper focuses on relevant problem, which business schools all over the world face and which is connected with the necessity to include concepts and instruments of strategic management valuable for the managers into the syllabus of the courses. In order to solve this problem it is necessary to define the requirements and expectations of the managers studying in business schools. The purpose of this paper is to determine the existing conformity of strategic management course syllabus and the Russian managers' perception of competitive advantage sources and the process of strategic management. During the empirical study a survey with the participants of the Executive MBA program (in one of the leading business schools in Russia) has been conducted. The aim of it is to reveal the expectations towards syllabus of "Strategic management" course.

(c) Санкт-Петербургский государственный университет, 2017 
The results of the analysis indicate that managers link the sources of competitive advantage with better position of the company in the external environment, that leads to greater interest in learning strategic tools which are appropriate for its detecting. The findings raise serious challenges for strategic management teaching and put into question the usefulness of proactive development of competences in strategic management education.

Keywords: «Strategic Management» course, business school, education for managers, teaching methods.

\section{ВВЕДЕНИЕ}

Роль и место бизнес-образования в современном обществе трудно переоценить: содействуя развитию управленческих компетенций и формированию или корректировке моделей поведения настоящих или будущих бизнес-лидеров, в идеале оно должно способствовать как повышению конкурентоспособности отдельных компаний, так и устойчивому развитию национальной экономики. В последние десятилетия система бизнес-образования в целом и ее ключевые игроки - бизнес-школы - сталкиваются с серьезной критикой. Ее отражением, в частности, являются активные дискуссии в ведущих мировых академических журналах по менеджменту в отношении текущей ситуации и необходимости значительных перемен.

С критикой со стороны различных стейкхолдеров бизнес-школы сталкивались и на более ранних этапах развития бизнес-образования. Ее направления со временем менялись. Например, если в 1950-х гг. американская система бизнесобразования, безусловно наиболее развитая в мире, критиковалась в первую очередь за отсутствие серьезной научной базы, то ближе к концу ХХ столетия существенным замечаниям стали подвергаться другие аспекты деятельности бизнес-школ. Чаще всего отмечалась фрагментация преподаваемых дисциплин и научных исследований, связанная с ростом уровня специализации выполняемых задач и должностей в экономике и с разработкой все большего числа специализированных учебных дисциплин при явно недостаточном уровне их координации. Критика касалась также чрезмерного акцента на обучении способам решения конкретных проблем в ущерб развитию способности выявлять последние; сфокусированности на решениях и действиях, обеспечивающих краткосрочную доходность активов; слабого учета в содержании учебных дисциплин особенностей политико-правовой, экономической, технологической и социокультурной среды различных стран и т. д. Неоднократно отмечалась и ориентированность проводимых в бизнес-школах исследований скорее на развитие теорий и концепций, чем на решение практических проблем управления (см., напр.: [Минцберг, 2010; Pfeffer, Fong, 2002; Gurau, 2015; Harrington, Short, Hynes, 2015]). Некоторые авторы пошли в своей критике еще дальше: по мнению С. Гхошала, многие из худших примеров управленческой практики недавнего времени (дело Enron и др.) уходят корнями в идеи, разработанные представителями бизнес-школ за последние 30 лет [Ghoshal, 2005]. 
В этом свете логичными выглядят выводы о парадоксальности сложившейся ситуации. С одной стороны, бизнес-школы призваны с помощью программ образования и повышения квалификации в области управления и проведения научных исследований содействовать распространению в деловой среде концепций и инструментов, способных повысить конкурентоспособность бизнеса. С другой стороны, влияние бизнес-школ на реальную управленческую практику ослабевает, причем все возрастающую конкуренцию им в данной сфере составляют корпоративные университеты, тренинговые и консалтинговые компании и электронное обучение. Достаточно широкий резонанс в свое время вызвала работа [Pfeffer, Fong, 2002], в которой на основе анализа рейтингов лучших книг по бизнесу, по версии журнала Business Week и национального списка бизнес-бестселлеров, сделан вывод о том, что бизнес-школы не являются основным источником изданий, оказывающих непосредственное влияние на развитие управленческой мысли и практики. Авторы ссылаются на известную работу [Rigby, 2001], содержащую вывод о том, что управленческие идеи и инструменты, предложенные представителями бизнеса и консалтинга, в большей степени соответствуют потребностям практиков, применяются чаще и реже отклоняются ${ }^{1}$ по сравнению с теми, которые разработаны в школах бизнеса.

Подобная критика и следующие за ней выводы о необходимости проведения серьезных изменений в деятельности бизнес-школ, например продвижения к совместному с представителями бизнеса созданию знаний в области менеджмента, повысили интерес к оценке востребованности на практике различных управленческих концепций и инструментов и ее отражения в содержании учебных курсов и технологиях обучения [Porter, McKibbin, 1988; Mintzberg, Gosling, 2002; Mahoney, McGahan, 2007]. Неудивительно, что инструментарию стратегического менеджмента в связи с этим уделяется достаточное внимание.

Интересные в практическом плане выводы были сделаны, в частности, в [Clark, 1997], где анализируются результаты опроса более 400 практикующих членов Ассоциации стратегического менеджмента Новой Зеландии и британского Общества стратегического планирования в отношении использования ими 32 стратегических инструментов ${ }^{2}$. Данные инструменты были разделены на три группы в соответствии со стадиями стратегического процесса: оценка ситуации (организационный анализ и анализ внешней среды); стратегический анализ (разработка и оценка стратегических альтернатив и выбор конкретной стратегии) и реализация стратегии (составление детальных планов, их воплощение в жизнь и мониторинг). Еще более показательные результаты были получены в [Wright, Paroutis, Blettner, 2013]. Авторы поставили перед собой задачу не только идентифицировать наиболее полезные с практической точки зрения стратегические ин-

\footnotetext{
1 Доля компаний, прекративших использование данных идей и инструментов.

2 В этой и других работах под стратегическими инструментами понимаются технологии, методы, модели, подходы и методологии, используемые для поддержки принятия решений в сфере стратегического управления.
} 
струменты $^{3}$, но и выявить внутреннюю логику их выбора практиками. Опрос с помощью метода репертуарных решеток 46 практикующих менеджеров - слушателей курса по стратегическому менеджменту в одной из американских школ бизнеса - показал, что практики считают полезными стратегические инструменты, позволяющие идентифицировать критические факторы успеха и осознать конкурентные преимущества своих компаний. Кроме того, выяснилось, что менеджеры отдают предпочтение тем стратегическим инструментам, использование которых позволяет увидеть взаимосвязь явлений и процессов, помогает проводить анализ с различных ракурсов, приводит к появлению новых идей, облегчает коммуникации и обмен идеями, придает мышлению системный характер.

В условиях глобализации целого ряда факторов, влияющих на образовательную деятельность бизнес-школ (глобализация бизнеса и конкуренции, бурное развитие информационных технологий, усиление турбулентности деловой среды и др.), проблема большего соответствия содержания и методов преподавания управленческих дисциплин потребностям практики не менее остро стоит и перед российским бизнес-образованием. В связи с этим цель настоящей статьи - выявить соответствие содержания дисциплин, направленных на изучение стратегии организации, и представлений российских менеджеров об источниках конкурентного преимущества и процессе стратегического управления. Это позволило бы понять необходимость изменений в содержании соответствующих курсов и методах их преподавания.

Для реализации данной цели кратко рассмотрены основные подходы к ответу на главные вопросы стратегического управления, проведено сравнение содержания курсов по стратегическому менеджменту, реализуемых в ряде ведущих бизнес-школ Европы и США, и проанализированы результаты опроса 49 менеджеров и владельцев бизнеса, проходивших обучение на программе «Мастер делового администрирования для руководителей» в Высшей школе менеджмента СПбГУ в 2015-2016 гг. Поставленные задачи определили структуру статьи.

\section{СТЕРЖНЕВЫЕ ВОПРОСЫ СТРАТЕГИЧЕСКОГО МЕНЕДЖМЕНТА}

Для определения целей и структуры учебных дисциплин по стратегии необходимо выявить тренды в развитии стратегического управления. Как и во всех областях науки, направленных на решение прикладных задач, в стратегическом менеджменте новые знания нужны в тех ситуациях, с которыми менеджеры встречаются впервые. Развиваются новые теории, позволяющие отвечать на вызовы, с которыми руководители сталкиваются в своей практике. Рассмотрение взглядов

3 Респондентам, в частности, было предложено оценить практическую полезность следующих 12 стратегических инструментов: модели оценки пяти сил конкуренции и конкурентных стратегий M. Портера; SWOT-анализа; ресурсного подхода к стратегическому управлению; цепочки создания ценности; матрицы BCG; модели 7S McKinsey; сбалансированной системы показателей; стратегических часов Боумена; карты стратегических групп; стратегии голубого океана; анализа стратегических факторов. 
на развитие стратегии в исторической ретроспективе позволяет выделить возможные направления разработки курсов [Greiner, Bhambri, Cummings, 2003].

Предмет стратегического управления состоит в «выяснении источников и механизмов создания и обеспечения устойчивых преимуществ фирм, обеспечивающих им присвоение экономических выгод, недоступных соперникам» [Катькало, 2008 , с. 52]. Таким образом, содержание стратегического менеджмента дает ответ на два ключевых вопроса: что может являться источником конкурентного преимущества и какие действия должна предпринять организация для его идентификации, получения и использования? И если необходимость получить ответ на них признается как академическим сообществом, так и практиками, то сами ответы отличаются большим разнообразием и обусловливают различные подходы к формированию стратегии.

При поиске конкурентного преимущества существует два основных подхода. Представители первого связывают его прежде всего с позиционным превосходством [Портер, 2016]. Чтобы получить больший финансовый результат, чем у среднестатистического конкурента, нужно занять доминирующее положение или выгодную рыночную нишу. Привлекательность того или иного сектора экономики может быть связана с отсутствием жесткой конкуренции, которая, в свою очередь, обусловлена наличием меньшего числа игроков, быстрым ростом рынка или высокими входными барьерами [Кэмпбелл, 2015]. При позиционном подходе основное внимание уделяется анализу цен и затрат, поведения конкурентов и запросов потребителей. Это может позволить найти решения, способные помочь в создании дифференцированных продуктов, за которые покупатели будут готовы платить больше, или привести к сокращению издержек производства и реализации.

Второй подход связан с внутренними возможностями организации - eе превосходством в ресурсах [Коллиз, Монтгомери, 2003; Барни, 2009] или в осуществлении процессов компании [Хамел, Прахалад, 2002; Тис, 2009]. Каждую организацию отличает набор ресурсов, которыми она обладает. Ресурсы, адекватные рыночной ситуации, формируют стратегические возможности фирмы и обеспечивают ей конкурентное преимущество. Но даже при наличии активов, уступающих по «качеству» активам других компаний, добиться лучших результатов можно за счет лучшей организации процессов. В ресурсной концепции основное внимание уделяется формированию портфеля ресурсов и компетенций, а также развитию внутренних способностей, которые позволяют приспосабливаться к изменениям во внешней среде. Причем на протяжении последних десяти лет речь все чаще идет об организационных возможностях «второго порядка», способствующих считыванию сигналов о переменах и быстрой адаптации к происходящим изменениям [Ривз, Даймлер, 2011]. Наиболее значимыми в такой ситуации становятся нематериальные ресурсы - человеческий и интеллектуальный капитал.

Необходимо отметить, что в последние годы появились утверждения о завершении эры конкурентного преимущества. Высокий динамизм внешней среды 
и постоянно происходящие изменения приводят к тому, что создать устойчивое конкурентное преимущество невозможно [McGrath, 2013]. Аргументы, которые используются против конца эпохи конкурентного преимущества, связаны с тем, что, несмотря на сложности современных компаний, которые обусловлены глобальным характером конкуренции, большей информированностью игроков и более легким доступом на рынок капитала, многие компании сохраняют лидерство на рынке в течение длительного времени [Мартин, 2015].

При этом представители различных подходов едины в понимании того, что конкурентное преимущество стало неустойчивым и расширился спектр возможностей для его создания, среди которых упоминаются новые бизнес-модели, например двусторонние платформы и развитие экосистем [Мартин, 2015; Markides, 2015].

Ответ на вопрос о том, каким образом формировать стратегию, также неоднозначен. Еще в 1978 г. Г. Минцберг [Mintzberg, 1978], описывая подходы к разработке стратегии, указывал, что организации, с одной стороны, разрабатывают планы на будущее (намеченная стратегия), а с другой - выводят принципы поведения из прошлого опыта (осуществляемая стратегия). Даже в условиях медленно меняющейся и хорошо предсказуемой внешней среды не все намеченные стратегии реализуются на практике. Это объясняется сложностью безошибочного предвидения и необходимостью адаптации к изменениям, которые произошли после того, как план составлен.

При увеличении динамизма внешней среды формирование планов как процесс, начинающийся с постановки целей, включающий анализ внешних и внутренних факторов и завершающийся разработкой стратегий и мероприятий по ее реализации, все больше подвергается критике. Если будущее характеризуется значительной неопределенностью, то формулирование стратегии с помощью жестко регламентированных процедур использования аналитических методов и выбора стратегического варианта может быть не только бесполезным, но и вредным [Courtney, Kirkland, Viguerie, 1997]. В такой ситуации более конструктивными могут оказаться проактивные действия, направленные на изменение отраслевой среды или экосистемы в соответствии с собственным видением, и стратегия предполагает создание новых рыночных возможностей. Некоторые компании понимают стратегию как «своевременные решения», «некоторые ключевые инициативы» или разновидность «адаптации к сложившимся условиям» [Cespedes, 2015]. Однако рост непредсказуемости внешней среды не должен служить поводом для отказа от стратегии, так как вопросы выхода на рынок и обеспечения приемлемых результатов деятельности нельзя оставлять без внимания.

Поскольку разные сферы бизнеса характеризуются различным уровнем предсказуемости и неодинаковой податливостью, справедливо вести речь о неодинаковых подходах к формированию стратегии в разных отраслях [Ривз, Даймлер, 2011]. В неизменных и стабильных условиях к разработке стратегии хорошо применимы классические подходы. В условиях непредсказуемых отраслей, слабо под- 
дающихся изменениям, разработка долгосрочных планов не приносит пользы, и деятельность по разработке стратегии может сводиться к формулированию и тестированию гипотез, причем акцент делается на внутренние возможности компании. В условиях непредсказуемой, но податливой среды организации уделяют основное внимание выявлению перспективных новых рынков и формированию обширных экосистем.

Ответы на вопросы об источниках конкурентного преимущества и способах формирования стратегии определяют содержание и структуру программ обучения. Разработка программы учебной дисциплины, посвященной стратегии, предполагает выявление концепции, которая будет доминировать, и определение тех инструментов, которые позволят повысить качество принимаемых стратегических решений.

\section{СОДЕРЖАНИЕ ПРОГРАММ УЧЕБНОЙ ДИСЦИПЛИНЫ «СТРАТЕГИЧЕСКИЙ МЕНЕДЖМЕНТ» В ВЕДУЩИХ БИЗНЕС-ШКОЛАХ}

Университеты и бизнес-школы играют важную роль в создании и распространении знаний в области стратегического управления как через научные труды ученых, так и через образовательные программы [Whittington et al., 2003]. Курсы в области стратегического управления могут иметь различные названия, например: «Стратегическое планирование» (Strategic Planning), «Реализация стратегии» (Strategic Implementation), «Стратегический анализ» (Strategic Analysis), «Конкурентная и корпоративная стратегия» (Competitive and Corporate Strategy) [Rubin, Dierdorff, 2009]. Р. Грант [Грант, 2008], анализируя основные подходы к формированию содержания курсов по стратегическому менеджменту, выделил два альтернативных направления: преподавание политики бизнеса и стратегический анализ. Первый подход предполагает акцент на практике менеджмента, формировании преподавательского состава из числа в первую очередь руководителей компаний и консультантов, при этом основное внимание уделяется стратегическому лидерству. Основным методом преподавания является кейс-стади. Второй подход сконцентрирован на изучении концепций получения прибыли (например, положения отраслевой экономики, теории рикардианской ренты) и реализуется в основном профессорами, имеющими ученую степень в смешанных областях знаний. Особая роль здесь отводится идентификации, созданию и присвоению ценности. Необходимо отметить, что содержание этих курсов в ведущих бизнесшколах мира очень близко по тематикам и отражает развитие теории стратегического управления в целом.

Для того чтобы продемонстрировать представленные выше наблюдения, были выбраны курсы в области стратегии нескольких ведущих бизнес-школ мира, являющихся лидерами в области преподавания и создания научной мысли в данной сфере и имеющих открытый доступ к информации о содержании учебных программ. Выбор школ осуществлялся на основе рейтинга QS Global 
200 Business Schools Report ${ }^{4}$, который составлен компанией QS TOP MBA с помощью опроса рекрутеров о компетенциях выпускников бизнес-школ в области стратегии. Были выбраны четыре из первых 16 вошедших в рейтинг школ: две американские - Гарвардская школа бизнеса Гарвардского университета (Harvard University, Harvard Business School), Школа бизнеса им. У. Хааса Калифорнийского университета (University of California - Berkley, Haas School of Business); две европейские - Лондонская школа бизнеса (London Business School) и Высшая коммерческая школа Парижа (HEC Paris). Кроме того, было проанализировано содержание курсов Высшей школы менеджмента Санкт-Петербургского государственного университета, признанной лучшей бизнес-школой Восточной Европы согласно рейтингу EdUniversal, а также школы на постсоветском пространстве Балтийского института менеджмента (Baltic Management Institute) (табл. 1), первой из бизнес-школ Восточной Европы и Северных стран получившей на максимально возможный срок аккредитацию Европейского фонда развития менеджмента (European Foundation for Management Development).

Выбор образовательных курсов в области стратегии был обусловлен подходом к сущности стратегического управления как идентификации конкурентных преимуществ и способов их достижения [Катькало, 2008, с. 52]. Не рассматривались курсы, выходящие за рамки указанного определения, например по стратегии управления инновациями, управлению глобальными стратегиями, которые направлены на формирование иных знаний и компетенций.

Для анализа были выбраны курсы: «Корпоративная стратегия» (Corporate Strategy), «Стратегия» (Strategy), «Стратегический менеджмент» (Strategic Management), «Деловая и корпоративная стратегия» (Business and Corporate Strategy). Все эти курсы нацелены на формирование компетенций, связанных с умением выработать стратегические альтернативы, сделать стратегический выбор и успешно реализовать стратегические решения, направленные на достижение устойчивого конкурентного преимущества.

Как видно из табл. 1, основная проблематика, которая освещается в рамках данных курсов в соответствии с выделенными целями и задачами, сводится к анализу: внешней (макро- и мезо-) и внутренней среды организации, конкурентной среды, источников конкурентного преимущества, принимаемых стратегических решений. Такой подход полностью соответствует развитию научной мысли в области стратегического управления. Однако, как отмечается в [Greiner, Bhambri, Cummings, 2003], содержание курсов по стратегии ведущих бизнес-школ лишено практической ориентации и излишне теоретизировано. Данный факт, по мнению авторов указанной статьи, можно объяснить преобладанием среди преподавателей курсов по стратегии профессоров с образованием в области отраслевой экономики и теории организации, которые придерживаются преимущественно научного подхода в своей работе.

${ }^{4}$ QS Top MBA: http://www.topmba.com/mba-rankings/specialization/strategy (дата обращения: 04.02.2017). 
Обучение стратегии в бизнес-школах: современные вызовы

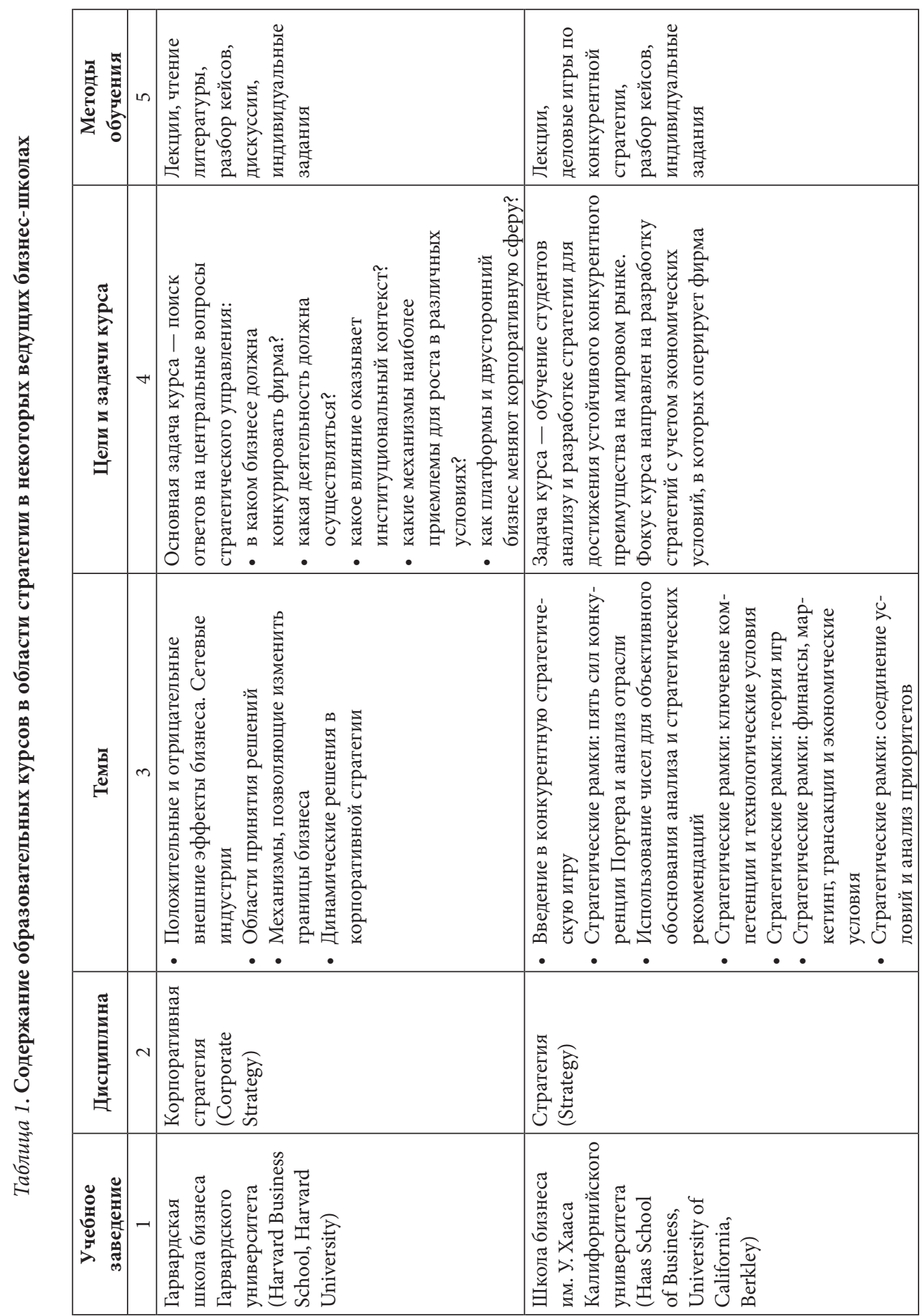




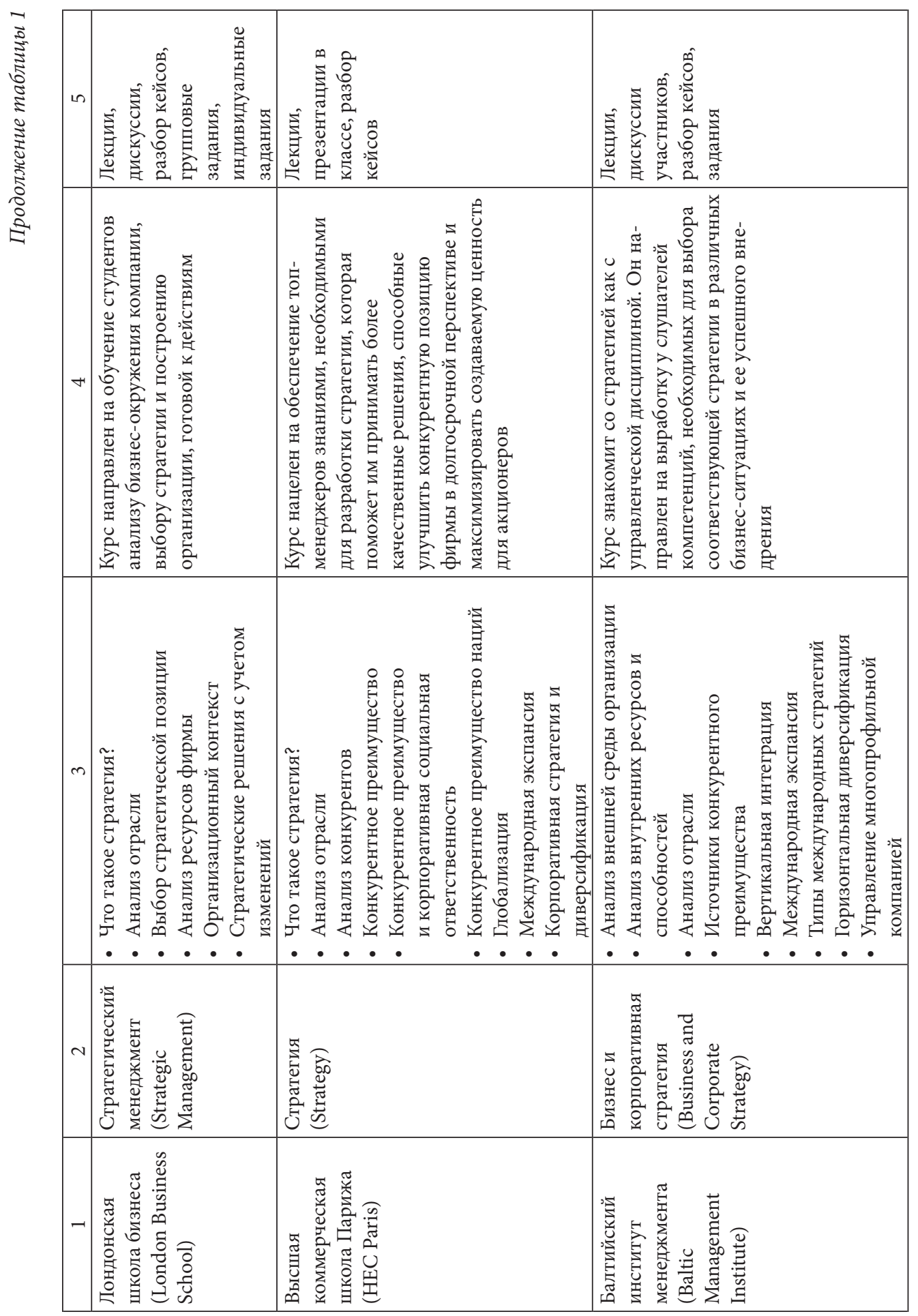


Обучение стратегии в бизнес-иколах: современные вызовы

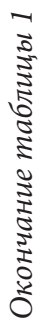

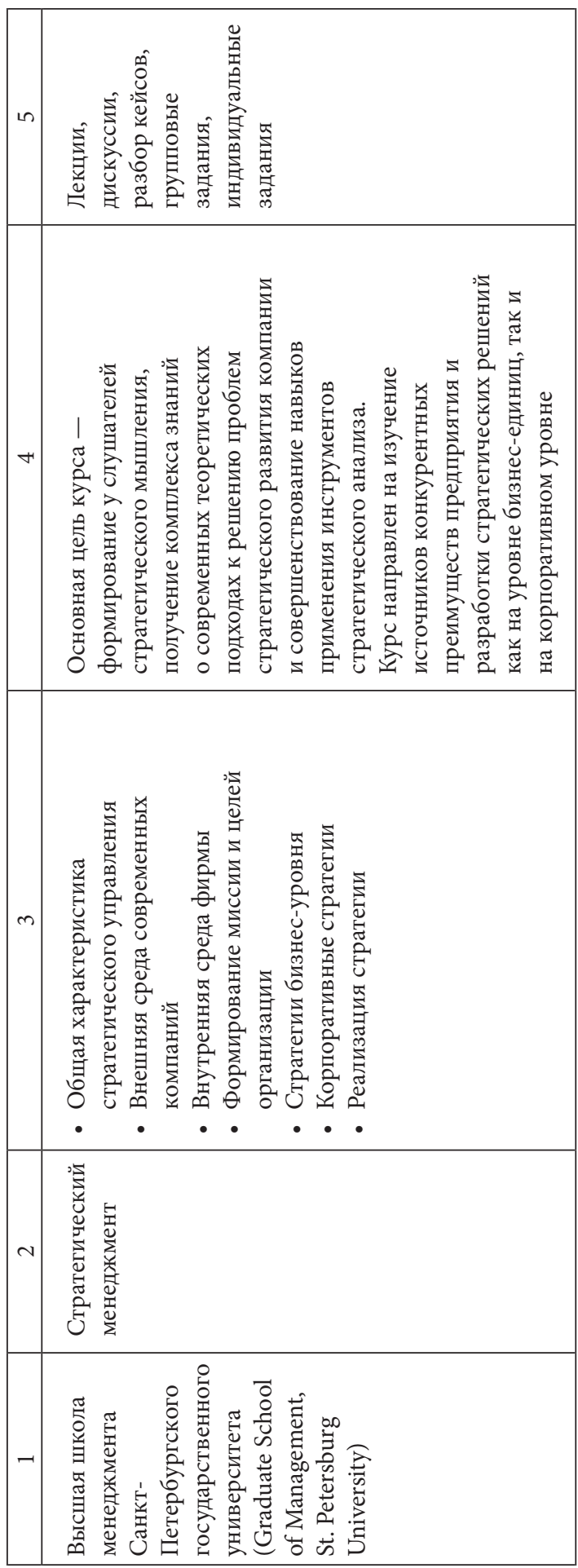


Возрастающая взаимозависимость явлений в мире и влияние изоморфизма ускоряют процесс распространения новой стратегической мысли [Whittington et al., 2003], и периодически в качестве реакции на изменения во внешней среде в курсах по стратегическому управлению появляется новая тематика, например касающаяся электронного бизнеса либо ответственного лидерства. Тем не менее базовые курсы по стратегическому управлению имеют схожее содержание.

\section{РЕЗУЛЬТАТЫ ОПРОСА СЛУШАТЕЛЕЙ ПРОГРАММЫ ЕМВА}

Описание выборки. Для выявления представлений обучающихся на программах для руководителей об источниках конкурентного преимущества и методах формирования стратегий нами был проведен опрос слушателей программы «Мастер делового администрирования для руководителей», проходивших обучение в Высшей школе менеджмента Санкт-Петербургского государственного университета (ВШМ СПбГУ) в 2015-2016 гг. Анкета охватывала три блока вопросов: первый из них был направлен на выявление характеристик респондентов, включая занимаемую ими должность, размер компании, наличие опыта принятия стратегических решений, а также предыдущий опыт изучения концепций и инструментов стратегического менеджмента; второй определял оценку важности респондентами различных элементов стратегического процесса и источников конкурентного преимущества компании; третий блок содержал вопросы о возможности формализации процесса стратегического менеджмента, а также использования различных концепций в практике управления.

Количество слушателей составило 78 человек, количество заполненных анкет - 49. Среди них - 45\% владельцы бизнеса, $41 \%$ - руководители высшего и $14 \%$ - среднего звена. Распределение компаний, в которых работают слушатели, по размеру на крупные, средние и малые приведено на рис. 1.

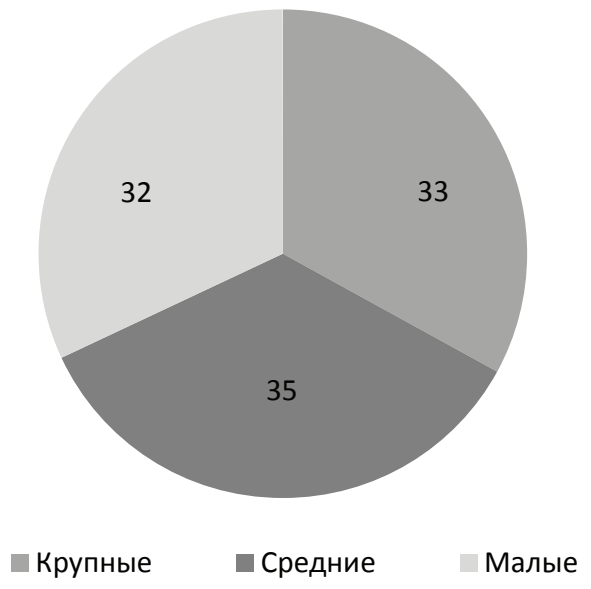

Puc. 1. Распределение представленных респондентами компаний по размеру, \% 
Большинство респондентов (63\%) указали, что участие в разработке стратегии компании является частью их должностных обязанностей; $14 \%$ респондентов отметили, что принятие стратегических решений не входит в их обязанности, однако они имеют право совещательного голоса при обсуждении подобных вопросов. Еще $18 \%$ респондентов периодически участвуют в принятии решений. Никогда не участвовали в процессе разработки только 4\%. Практически все владельцы бизнеса отметили, что стратегическое управление входит в круг их обязанностей.

Респонденты описали свой опыт изучения концепций и инструментов стратегического менеджмента до поступления на программу «Мастер делового администрирования», при этом можно было выбрать более одного варианта ответа (табл. 2). Как видно, наиболее востребованным способом было изучение этих вопросов по статьям в деловой периодической литературе и бизнес-бестселлерах.

\section{Таблица 2. Способы изучения концепций и инструментов стратегического менеджмента}

\begin{tabular}{|c|c|}
\hline \multicolumn{1}{|c|}{ Способы } \\
изучения & $\begin{array}{c}\text { Доля респондентов, } \\
\text { выбравших данный вариант } \\
\text { ответа, \% }\end{array}$ \\
\hline Учебники & 6,1 \\
\hline Бизнес-бестселлеры & 20,4 \\
\hline Статьи в деловой периодической литературе & 28,6 \\
\hline Интернет-ресурсы & 16,3 \\
\hline Бизнес-тренинг & 16,3 \\
\hline Курсы повышения квалификации & 12,2 \\
\hline Обучение на программе ЕМВА & 2,0 \\
\hline Никогда не изучал (а) & 53,1 \\
\hline
\end{tabular}

Большинство респондентов ответили, что не имеют опыта изучения концепций и инструментов стратегического менеджмента (53,1\%). При этом отсутствие знаний не связано с участием или неучастием в принятии стратегических реше- 
ний: среди тех, кто указал, что участвует в принятии стратегических решений, изучавших и не изучавших концепции стратегического менеджмента примерно одинаково.

Значимость источников конкурентного преимущества и формализации стратегического процесса. Как отмечалось ранее, основными в стратегическом менеджменте являются вопросы определения источников конкурентного преимущества и способов его получения. Для идентификации того, связывают ли респонденты источники конкурентного преимущества с позиционным превосходством или с превосходством в ресурсах, респондентам было предложено ответить на ряд вопросов. Первый из них касался диагностики основных элементов стратегического менеджмента (рис. 2) 5 .

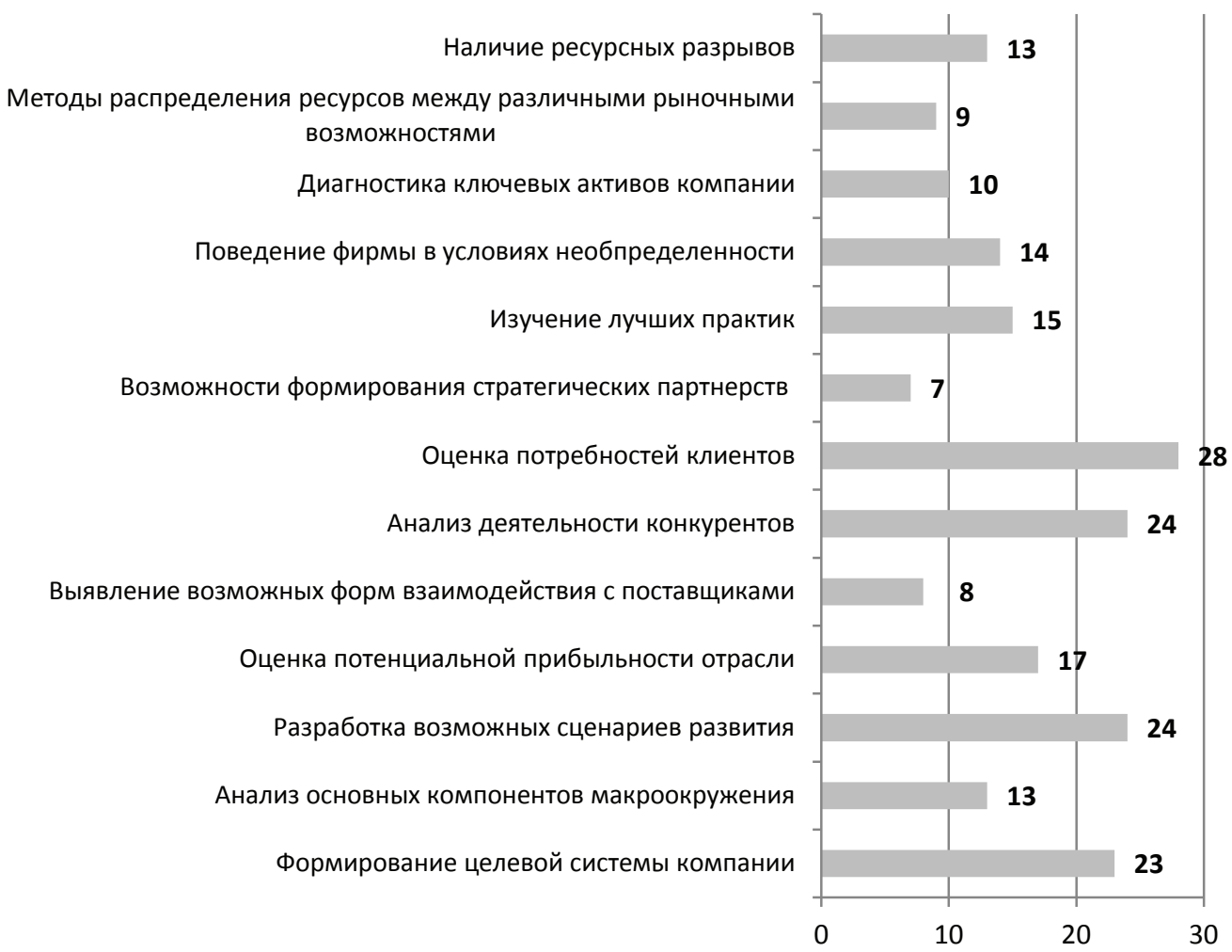

Рис. 2. Степень важности диагностики основных элементов стратегического менеджмента по оценке респондентов, доля, \%

Как видно из представленных данных, большинство респондентов отмечают в качестве «крайне важных» те элементы, которые связаны с позицией компании в отрасли. Основное внимание, по мнению слушателей, должно быть направле-

5 При ответе на вопрос респонденты должны были выбрать один из следующих вариантов: «крайне важно», «важно», «не очень важно», «совсем не важно». 
но на оценку потребностей клиентов и деятельность конкурентов. Помимо этого, респонденты относят разработку возможных сценариев развития к особо значимым областям. Ресурсный потенциал компании и связанные с ними методы диагностики ключевых активов компании респонденты считают менее важными. Об этом свидетельствуют относительно низкие значения оценки важности диагностики ключевых активов компании, распределения ресурсов между различными рыночными возможностями и наличие ресурсных разрывов.

Полученные результаты позволяют вести речь о том, что на сегодняшний день большинство менеджеров ориентируются в основном на позиционное превосходство, а не на преимущество в ресурсном потенциале. При этом оценки менеджеров компаний различных размеров не варьируются. Исключение составляет показатель, связанный с оценкой потребности клиентов: представители малого бизнеса придают этому аспекту большее значение по сравнению с менеджерами средних и крупных компаний.

При изучении источников конкурентного преимущества респондентам предлагалось оценить важность для достижения успеха позиционных, ресурсных и процессных составляющих. Результаты оценки представлены на рис. 3. Респонденты в большей степени ориентированы на позиционные преимущества: достижение сильной рыночной позиции и предложение уникального продукта. Обеспечению лучшей позиции по активам в сравнении с конкурентами отводится значительно меньшая роль: лишь 16\% респондентов указали, что данный источник конкурентного преимущества является «крайне важным». Можно предположить, что развитию ресурсного потенциала и формированию стратегии компании на основе уникальных ресурсов менеджеры российских компаний будут уделять меньшее внимание.

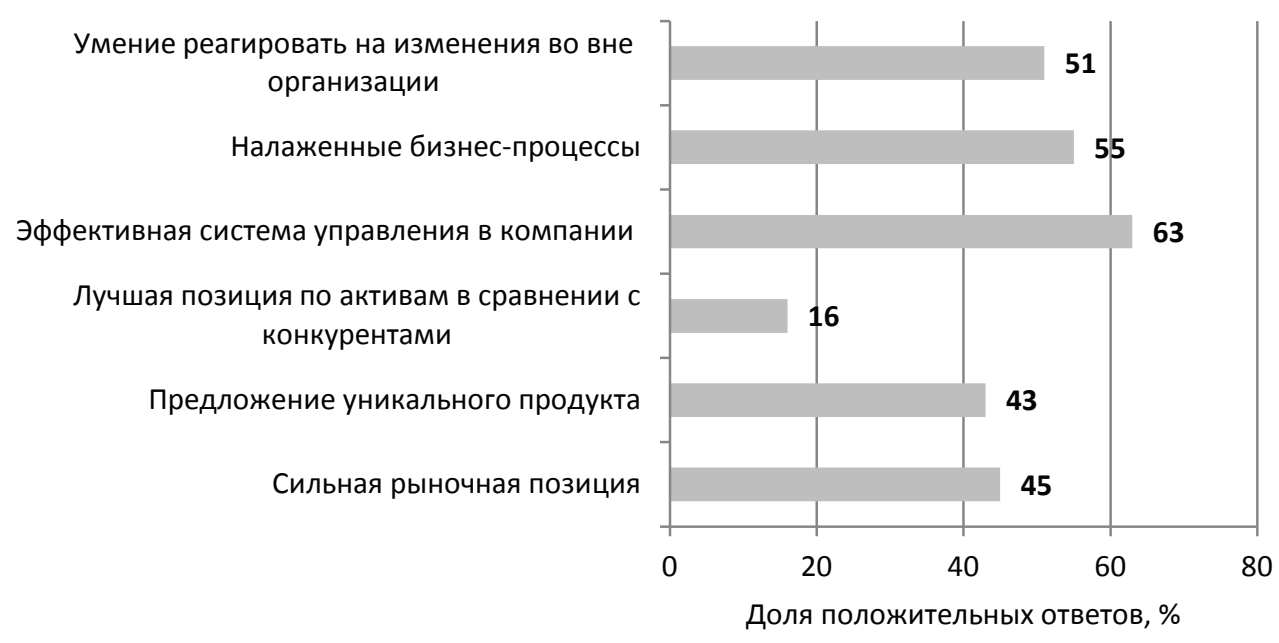

Puc. 3. Степень важности различных факторов достижения успеха по оценке респондентов, доля, \% 
Особое значение респонденты придают организации процессов в компании. Практически не оказалось респондентов, указавших, что эффективная система управления и налаженные бизнес-процессы не играют роли для достижения успеха компании. При этом большинство респондентов отметили умение реагировать на изменения во внешней среде как необходимый элемент стратегического управления. При существенной важности факторов внешней среды и достижения выгодной конкурентной позиции данный ответ позволяет говорить скорее о реактивном, а не проактивном подходе к управлению.

Необходимо подчеркнуть, что эффективной системе управления уделяется большее внимание по мере увеличения размера компании. Так, в малых компаниях 7\% респондентов отметили данный аспект как «крайне важный», в средних компаниях $-11 \%$ и в крупных компаниях $-13 \%$ респондентов. Вместе с тем умение реагировать на изменения во внешней среде не зависит от размера компании респондентов.

По мнению Р. Гранта [Грант, 2008], на самом общем уровне стратегия - это планирование способов, с помощью которых организация может достигать поставленных целей. Основная часть респондентов полагает, что формирование целевой системы в компании является «важным» и «крайне важным» направлением стратегического процесса. Интересно, что из числа респондентов, которые считают данные аспекты не очень важными, подавляющее количество представлено топ-менеджерами и владельцами бизнеса (рис. 4).

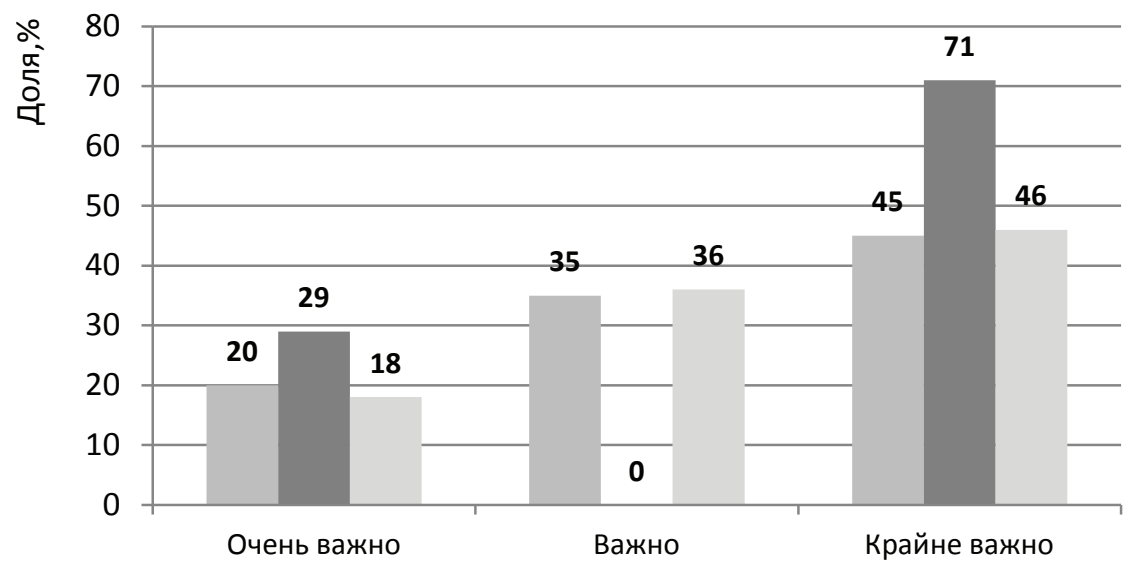

Топ-менеджеры $\square$ Менеджеры среднего звена Владельцы бизнеса

Puc. 4. Степень важности формирования целевой системы в зависимости от должности респондентов, доля, \%

Как отмечалось, природа стратегии зависит от стабильности и предсказуемости окружающей среды. При рассмотрении эволюции стратегического менедж- 
мента выделяются проблемы, доминировавшие в различное время и отражавшие ответы на динамизм и сложность внешней среды [Грант, 2008]. Предполагается, что основные трудности, с которыми сталкивались компании, менялись на протяжении последних 60 лет. Если в 1950-е гг. основное внимание в стратегическом управлении уделялось финансовому контролю, то в 1960-е гг. акцент был перенесен на планирование роста и портфельное планирование. С конца 1970-х гг. выбор отраслей и рынков стал доминирующей темой в стратегии компаний. В конце 1980-х гг. произошло фокусирование стратегии на основных источниках конкурентного преимущества. Повышение динамизма внешней среды и снижение ее предсказуемости в 2000-х гг. привело к тому, что основное внимание стало уделяться гибкости скорости реагирования на возможные изменения. Для оценки того, как российские менеджеры воспринимают основные вызовы, стоящие перед компаниями, им был задан вопрос о наиболее важных задачах менеджмента многопрофильных компаний. При этом предполагалось, что они должны дать оценку как для российских компаний в целом, так и для своей компании в частности (рис. 5).

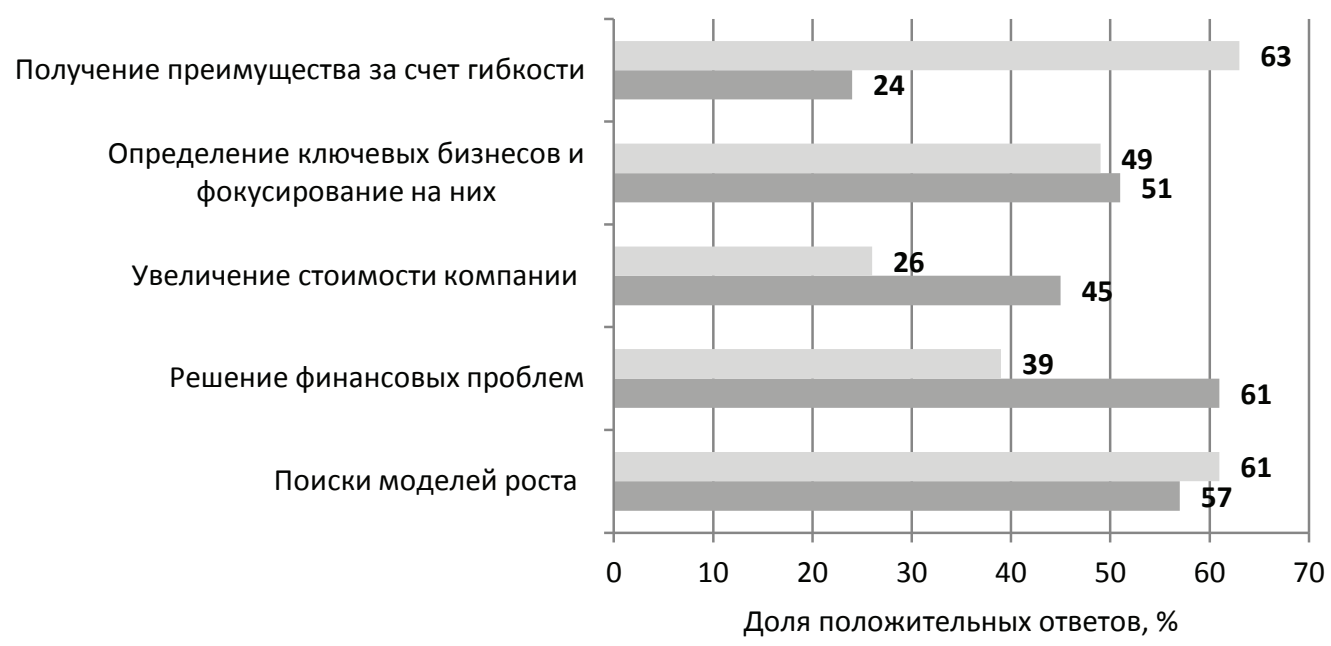

Для компании респондента Вля российских компаний в целом

Puc. 5. Основные проблемы компаний по оценке респондентов, доля, \%

Как видно из рис. 5, для российских компаний в целом респонденты считают наиболее важными задачи решения финансовых проблем и поиска моделей роста. Получение преимуществ за счет гибкости отмечено в качестве важной задачи только $1 / 4$ респондентов. Это позволяет предположить, что российские менеджеры считают важнейшими проблемами компаний те, которые были свойственны американским и европейским компаниям в 1950-1970-е гг. Третий по по- 
пулярности ответ связан с определением ключевых бизнесов и фокусировании на них. Это свидетельствует о том, что вопросы идентификации конкурентного преимущества рассматриваются менеджерами как значимые элементы стратегического управления. Обращает на себя внимание тот факт, что ресурсный потенциал компании не играет важной роли в качестве источника конкурентного преимущества, хотя в развитии управленческой мысли поиск источников конкурентного преимущества и идентификация ключевых ресурсов и способностей рассматривались в тесной связи.

Однако при определении наиболее важных областей для своих компаний оценки менеджеров меняются. Если поиски моделей роста по-прежнему актуальны, то решение финансовых проблем становится менее значимым, в то время как гибкость организации выходит на первое место. Возможно, это связано с тем, что слушатели программы ЕМВА ведущей бизнес-школы в России воспринимают себя как носителей наиболее современных подходов к управлению российскими компаниями.

Помимо источников конкурентного преимущества, развитие теории и практики стратегического менеджмента связано с развитием подходов к формализации стратегии, что, в свою очередь, находится под влиянием динамизма внешней среды. Подавляющее число респондентов (86\%) считают, что компания должна уделять время анализу внешней среды, а наличие в компании стратегии позволяет добиваться лучших результатов (96\%). При этом лишь 2/3 респондентов полагают, что наличие формализованной стратегии облегчает процесс построения организационных отношений. Такое же количество опрошенных утверждают, что сложности реализации напрямую связаны с качеством разработки стратегии и хорошо продуманная стратегия должна быть реализована. При этом формализация стратегии выступает необходимым условием ее успешности: менее половины респондентов отметили, что креативность в создании бизнес-моделей важнее, чем наличие формализованной стратегии.

Основная часть респондентов (60\%) указывает, что разработка стратегии предполагает вовлеченность в процесс не только высшего руководства. Российские менеджеры скептически относятся к необходимости привлечения профессиональных консультантов к формированию стратегии.

Взгляды на источники конкурентного преимущества определяют и методы, которые применяют менеджеры при разработке стратегии: если технологию SWOT-анализа знают и используют около 70\% респондентов, то с концепцией динамических способностей знакомы только 6\% из них.

Итак, большинство российских менеджеров уверены в том, что наличие формализованной стратегии способствует достижению компанией успеха. При этом источники конкурентного преимущества связываются с достижением позиционного превосходства. Интересно установить, является это особенностью российской системы управления или характерно для стран, находящихся на одном уровне экономического развития. 
Предпочтения в отношении методов обучения. Не менее важным является вопрос о методах преподавания стратегического менеджмента. Наиболее эффективным методом респонденты считают интерактивные лекции преподавателей, при этом такой востребованный сегодня в европейских и американских бизнесшколах метод, как видеолекции, позитивно воспринимается лишь менее 1/5 респондентов.

Объяснение, видимо, нужно искать в том факте, что более половины респондентов никогда не изучали концепции и инструменты стратегического менеджмента, в результате чего интерактивные лекции рассматриваются ими как способ формирования первичной базы знаний в данной области, в то время как для остальных они служат средством систематизации знаний, полученных в ходе изучения различных источников. Возможно, свою роль в формировании подобной оценки сыграло и то, что институционализация некоторых современных технологий обучения в российском бизнес-образовании еще далека от завершения.

Обращает на себя внимание и то обстоятельство, что в отношении такой популярной технологии обучения, как кейс-стади, респонденты отдают предпочтение кейсам, разработанным на материалах российских компаний, действующих в родной правовой, экономической и социокультурной среде, однако при этом обсуждение опыта коллег по обучению считают эффективным лишь 28\% респондентов. Более половины опрошенных предпочитают выполнение заданий в рамках курса «Стратегический менеджмент» на материалах своей организации, что позволяет, наряду с развитием компетенций в области стратегического анализа и принятия стратегических решений, под несколько иным углом зрения взглянуть на текущее положение компании в конкурентной среде и внести вклад в анализ ее стратегических проблем и выработку путей их решения. При этом следует отметить, что использование кейс-стади в качестве основного метода преподавания стратегических дисциплин достаточно активно подвергается критике рядом авторов (см., напр.: [Минцберг, 2010; Greiner, Bhambri, Cummings, 2003]), которая связана с тем, что он не способствует развитию аналитического образа мышления менеджеров.

Как показали результаты анкетирования ожиданий и представлений слушателей российской бизнес-школы, существует разрыв между тем, как они рассматривают факторы, обеспечивающие компании лучшие результаты экономической деятельности, и тем, как расставляются приоритеты в выборе источников конкурентного преимущества в современной теории стратегического управления и в базирующихся на них стратегических дисциплинах.

\section{ЗАКЛЮЧЕНИЕ}

Бизнес-школы играют важную роль в создании конкурентного преимущества на уровне как отдельных компаний, так и национальной экономики в целом. Профессиональная подготовка менеджеров в них должна осуществляться в со- 
ответствии с учетом актуальных управленческих задач и потребностей. Бизнесобразование призвано формировать содержание учебных курсов, обладающих реальной полезностью для бизнеса.

В связи с этим в данной статье предпринята попытка дать оценку соответствия содержания курсов по стратегии и представлений российских менеджеров об источниках конкурентного преимущества компаний и процессе стратегического управления. Анализ литературы показал, что бизнес-школы как основные провайдеры бизнес-образования должны ответить на критику в отношении растущего разрыва между потребностями управленческой практики и содержанием учебных дисциплин. Дисциплина «Стратегический менеджмент» не является в этом отношении исключением: полезность отдельных концепций и стратегических инструментов для практикующих менеджеров пока не столь очевидна. При обучении в бизнес-школах они ожидают получить знания и навыки, которые позволили бы именно их компаниям достичь высоких экономических результатов.

Анализ программ стратегических дисциплин ведущих бизнес-школ показал, что их содержание в значительной степени унифицировано и предполагает изучение факторов как внешней, так и внутренней среды, формирующих возможности для выявления, создания и удержания конкурентного преимуществ, при этом акценты могут быть сделаны на позиционное, ресурсное или процессное превосходство.

Как свидетельствуют результаты опроса, проведенного среди слушателей программы ЕМВА ВШМ СПбГУ, они связывают источники конкурентного преимущества в основном с лучшей позицией компании во внешней среде, что приводит к большей заинтересованности в изучении стратегических инструментов, позволяющих ее диагностировать. Что касается отношения к формализации стратегического процесса, то предпочтение отдается не гибким подходам, а регламентированным процедурам формирования стратегии.

Все это создает ряд вызовов при формировании содержания дисциплин в области стратегии и ставит вопросы для дальнейших исследований:

1) является ли ориентация на внешнюю среду при формировании стратегии компании особенностью исключительно российских менеджеров или можно говорить об общих подходах к обнаружению источников конкурентного преимущества, определяющих содержание дисциплины, для стран со схожим уровнем экономического и институционального развития;

2) должны ли бизнес-школы учитывать представления слушателей при разработке и преподавании учебных курсов или расширять их взгляды в области стратегического управления за счет включения в содержание дисциплины прорывных концепций, к восприятию которых слушатели еще недостаточно готовы;

3) будет ли знание концепций, опережающих современную российскую практику, полезным для менеджеров и смогут ли они улучшить позиции компаний, применяя их в деловой практике? 


\section{Литература}

Барни Дж. Б. 2009. Может ли ресурсная концепция принести пользу исследованиям в области стратегического управления? - Да. Российский журнал менеджмента 7 (2): 71-92.

Грант Р. 2008. Современньй стратегический анализ. 5-е изд. СПб.: Питер.

Катькало В. С. 2008. Эволюиия теории стратегического управления. 2-е изд. СПб.: Изд-во С.-Петерб. ун-та.

Коллиз Д. Дж., Монтгомери С. А. 2003. Конкуренция на основе ресурсов: стратегия в 1990-е гг. Вестник С.-Петербургского ун-та. Сер. Менеджмент (4): 186-208.

Кэмпбелл Э. 2015. Базовые принципы создания стратегии не изменились за последние 30 лет. Harvard Business Review Россия. URL: http://hbr-russia.ru/management/strategiya/p15898/ (дата обращения: 28.01.2017).

Мартин Р. 2015. По-прежнему остается всего лишь два вида конкурентного преимущества. Harvard Business Review Poccuя. URL: http://hbr-russia.ru/management/operatsionnoe-upravlenie/p15881/ (дата обращения: 28.01.2017).

Минцберг Г. 2010. Требуются управленцы, а не выпускники МВА. Жесткий взгляд на мягкую практику управления и систему подготовки менеджеров. М.: Олимп-бизнес.

Портер М. 2016. Конкурентная стратегия: Методика анализа отраслей и конкурентов. М.: Альпина Паблишер.

Ривз М., Даймлер М. 2011. Адаптивность как новое конкурентное преимущество. BCG Review (20): 9-19.

Тис Д. Дж. 2009. Выявление динамических способностей: природа и микрооснования (устойчивых) результатов компании. Российский журнал менеджмента 7 (4): 59-108.

Хамел Г., Прахалад К. К. 2002. Конкурируя за будущее. Создание рынков завтрашнего дня. М.: Олимп-Бизнес.

Cespedes F. V. 2015. Aligning strategy and sales. International Journal of Sales Transformation. 1 (1): $52-54$.

Clark D. N. 1997. Strategic management tool usage: A comparative study. Strategic Change 6 (7): $417-427$.

Courtney H., Kirkland J., Viguerie P. 1997. Strategy under uncertainty. Harvard Business Review 75 (6): 67-79.

Ghoshal S. 2005. Bad management theories are destroying good management practices. Academy of Management Learning and Education. 4 (1): 75-91.

Greiner L., Bhambri A., Cummings T. G. 2003. Searching for a strategy to teach strategy. Academy of Management Learning and Education 2 (4): 402-420.

Gurau G. 2015. Business education in the present society: Problems, challenges and solutions. Annals of the University of Oradea. Economic Science Series 24 (2): 583-590.

Harrington D., Short J. C., Hynes B. 2015. Changing times for management educators: Rethinking engagement with participatory forms of knowledge production. Irish Journal of Management 34 (1): 51-59.

Mahoney J. T., McGahan A. M. 2007. The field of strategic management within the evolving science of strategic organization. Strategic Organization 5 (1): 79-99.

Markides C. C. 2015. Research on business models: Challenges and opportunities. In: Ch. BadenFuller, V. Mangematin (eds.) Business Models and Modelling (Advances in Strategic Management, Volume 33). Bingley: Emerald Group Publishing Limited; 133-147.

McGrath R. G. 2013. The End of Competitive Advantage: How to Keep Your Strategy Moving as Fast as Your Business. Boston: Harvard Business Review Press.

Mintzberg H. 1978. Patterns in strategy formation. Management Science. 24 (9) : 934-948.

Mintzberg H., Gosling J. 2002. Educating managers beyond borders. Academy of Management Learning and Education 1 (1): 64-76. 
Pfeffer J., Fong C. T. 2002. The end of business schools? Less success than meets the eye. Academy of Management Learning and Education 1 (1): 78-85.

Porter L. W., McKibbin L. E. 1988. Management Education and Development: Drift or Thrust into the 21st Century? Hightstown, NJ: McGraw-Hill Book Co.

Rubin S. R., Dierdorff E. C. 2009. How relevant is the MBA? Assessing the alignment of required curricula and required managerial competencies. Academy of Management Learning \& Education 8 (2): 208-224.

Rigby D. 2001. Management tools and techniques: A survey. California Management Review 43 (2): 139-160.

Whittington R., Jarzabkowski P., Mayer M., Mounoud E., Nahapiet J., Rouleau L. 2003. Taking strategy seriously. Journal of Management Inquiry 12 (4): 396-409.

Wright R. P., Paroutis S. E., Blettner D. P. 2013. How useful are the strategic tools we teach in business schools? Journal of Management Studies 50 (1): 93-125.

\section{Russian language references translated into English}

Barney J. B. 2009. Mozhet li resursnaia kontseptsiia prinesti pol'zu issledovaniiam v oblasti strategicheskogo upravleniia? - Da [Is the resource-based "view" a useful perspective for strategic management research? Yes]. Rossiiskii zhurnal menedzhmenta 7 (2): 71-92. (In Russian)

Grant R. 2008. Sovremennyi strategicheskii analiz [Contemporary Strategy Analysis]. 5-e izd. St. Petersburg: Piter. (In Russian)

Kat'kalo V. S. 2008. Evoliutsiia teorii strategicheskogo upravleniia [Evolution of Strategic Management Theory]. 2nd ed. St. Petersburg: Izd-vo St. Petersburg State University. (In Russian)

Kolliz D. Dzh., Montgomeri S. A. 2003. Konkurentsiia na osnove resursov: strategiia v 1990-e gg [Competing on resources: Strategy in the 1990s]. Vestnik S.-Peterburgskogo universitetata. Seria Menedzhment (4): 186-208. (In Russian)

Kempbell A. 2015. Bazovye printsipy sozdaniia strategii ne izmenilis' za poslednie 30 let [The basic principles of creating strategies have not changed over the last 30 years]. Harvard Business Review Rossiia. URL: http://hbr-russia.ru/management/strategiya/p15898/ (accessed: 28.01.2017). (In Russian)

Martin R. 2015. Po-prezhnemu ostaetsia vsego lish' dva vida konkurentnogo preimushchestva [There are still only two types of competitive advantage]. Harvard Business Review Rossiia. URL: http:// hbr-russia.ru/management/operatsionnoe-upravlenie/p15881/ (accessed: 28.01.2017). (In Russian)

Mintsberg G. 2010. Trebuiutsia upravlentsy, a ne vypuskniki MBA. Zhestkii vzgliad na miagkuiu praktiku upravleniia i sistemu podgotovki menedzherov [Managers Are Required, not MBA Graduates. A Hard Look at Soft Management Practices and a Manager Training System]. Moscow: Olimpbiznes. (In Russian)

Porter M. 2016. Konkurentnaia strategiia: Metodika analiza otraslei i konkurentov [Competitive Strategy: Industries and Competitors Analyzing Methodology]. Moscow: Al'pina Pablisher. (In Russian)

Reevez M., Deimler M. 2011. Adaptivnost' kak novoe konkurentnoe preimushchestvo [Adaptability: The new competitive advantage]. BCG Review (20): 9-19. (In Russian)

Teece D. J. 2009. Vyiavlenie dinamicheskikh sposobnostei: priroda i mikroosnovaniia (ustoichivykh) rezul'tatov kompanii [Explicating dynamic capabilities: Nature and microfoundations of (sustainable) enterprise performance]. Rossiiskii zhurnal menedzhmenta 7 (4): 59-108. (In Russian)

Khamel G., Prakhalad K. K. 2002. Konkuriruia za budushchee. Sozdanie rynkov zavtrashnego dnia [Competing for the Future. Creating Markets for Tomorrow]. Moscow: Olimp-Biznes. (In Russian) 
Для цитирования: Арай Ю. Н., Верховская О. Р., Клёмина Т. Н. Обучение стратегии в бизнес-школах: современные вызовы // Вестник СПбГУ. Менеджмент. 2017. Т. 16. Вып. 2. С. 299321. DOI: 10.21638/11701/spbu08.2017.205.

For citation: Aray Y. N., Verkhovskaya O. R., Klemina T. N. Strategy teaching: Contemporary challenges. Vestnik of Saint Petersburg University. Management, 2017, vol. 16, issue 2, pp. 299-321. DOI: 10.21638/11701/spbu08.2017.205.

Статья поступила в редакцию 7 февраля 2017 г.; принята к печати 19 апреля 2017 г.

Конт актн а и н формация

Арай Юлия Николаевна — кандидат экономических наук; старший преподаватель;

Aray_yulia@gsom.pu.ru

Верховская Ольга Рафаиловна - кандидат экономических наук; доцент;

verkhovskaya@gsom.pu.ru

Клёмина Татьяна Николаевна - кандидат экономических наук; доцент; klemina@gsom.pu.ru

Aray Yulia N. — PhD, Senior Lecturer; Aray_yulia@gsom.pu.ru

Verkhovskaya Olga R. — PhD, Associate Professor; verkhovskaya@gsom.pu.ru

Klemina Tatiana N. — PhD, Associate Professor; klemina@gsom.pu.ru 